\title{
CHARACTERIZATION OF POLYMORPHIC CERIUM PHOSPHATES AS STUDIED BY SOLID-STATE HIGH-RESOLUTION ${ }^{31 P}$ NMR
}

\author{
HIROKAZU NAKAYAMA, AKI HAYASHI, MITSUTOMO \\ TSUHAKO, TARO EGUCHI* AND NOBUO NAKAMURA* \\ Kobe Pharmaceutical University and *Department of Chemistry, \\ Graduate School of Science, Osaka University
}

\begin{abstract}
In order to characterize various forms of layered cerium phosphates, ${ }^{31} \mathrm{P}$ MAS and CP/MAS NMR spectra were measured in the solid state. Two peaks around -10 and $-30 \mathrm{ppm}$ suggest them to be $\gamma$-type structure with the non-stoichiometric amount of hydration waters.
\end{abstract}

\section{Introduction}

Since layered zirconium phosphates were first synthesized by A. Clearfield et al. in $1964,{ }^{1,2)}$ extensive studies concerning the ion-exchange capability of these compounds were performed in 1970's. Recently, inorganic-organic hybrid materials with new functions have been tried to be synthesized using the layered phosphates. There are two types of layered phosphates, $\alpha$ - and $\gamma$-types. The difference of the physicochemical properties, such as ion-exchange capability, thermal stability and intercalation of organic compounds, in these two types of compounds ( $\alpha$ - and $\gamma$-types) is closely related to their structural differences. Single crystal structure analyses were only performed for $\alpha-\operatorname{Zr}\left(\mathrm{HPO}_{4}\right)_{2} \cdot \mathrm{H}_{2} \mathrm{O}$ and $\alpha$ $\mathrm{Zr}\left(\mathrm{HPO}_{4}\right)\left(\mathrm{NaPO}_{4}\right) \cdot \mathrm{H}_{2} \mathrm{O}$, because of the difficulty in synthesizing single crystals of layered phosphates.3,4) And the crystal structure of $\gamma$ - 
$\mathrm{Zr}\left(\mathrm{HPO}_{4}\right)_{2} \cdot 2 \mathrm{H}_{2} \mathrm{O}$ was resolved by Rietveld analysis of powder sample in 1995,5) and 31P MAS (Magic Angle Spinning) NMR in 1987.6) It was clear that $\gamma-\mathrm{Zr}\left(\mathrm{HPO}_{4}\right)_{2} \cdot 2 \mathrm{H}_{2} \mathrm{O}$ has two different phosphate groups, $\mathrm{H}_{2} \mathrm{PO}_{4}^{-}$and $\mathrm{PO}_{4}{ }^{3-}$, in the crystal. Thus, $\gamma$-zirconium phosphate should not be expressed in chemical formula as $\mathrm{Zr}\left(\mathrm{HPO}_{4}\right)_{2} \cdot 2 \mathrm{H}_{2} \mathrm{O}$, but as $\mathrm{Zr}\left(\mathrm{H}_{2} \mathrm{PO}_{4}\right)\left(\mathrm{PO}_{4}\right) \cdot 2 \mathrm{H}_{2} \mathrm{O}$. As it is sometimes difficult to elucidate the structure from powder X-ray diffraction, it is important to distinguish these two types by the other method.

Layered cerium phosphates are reported to have many polymorphic forms, $\mathrm{Ce}\left(\mathrm{HPO}_{4}\right)_{2} \cdot \mathrm{nH}_{2} \mathrm{O}(\mathrm{n}=0.33,1.33$ and 2$)$, depending on the number of hydration water.6) These forms exchange reversibly under the different humidity. In the case of layered zirconium and titanium phosphates, two polymorphic forms, $\mathrm{M}\left(\mathrm{HPO}_{4}\right)_{2} \cdot \mathrm{H}_{2} \mathrm{O}\left(\alpha\right.$-form) and $\mathrm{M}\left(\mathrm{H}_{2} \mathrm{PO}_{4}\right)\left(\mathrm{PO}_{4}\right) \cdot 2 \mathrm{H}_{2} \mathrm{O}(\gamma-$ form), have completely different structure as mentioned above and can be obviously distinguished by the number of hydration water. However, layered $\mathrm{Ce}\left(\mathrm{HPO}_{4}\right)_{2}$ • $1.33 \mathrm{H}_{2} \mathrm{O}$ has non-stoichiometric number of hydration water and can not be classified in the $\alpha$ - or $\gamma$-type by only the number of it. Recently, we showed that ${ }^{31 P}$ MAS NMR is a useful technique to know the local structure of layered phosphates. ${ }^{7)}$ Thereupon, we applied this method to $\mathrm{Ce}\left(\mathrm{HPO}_{4}\right)_{2} \cdot \mathrm{nH}_{2} \mathrm{O} \quad(\mathrm{n}=0.33, \quad 1.33$ and 2).

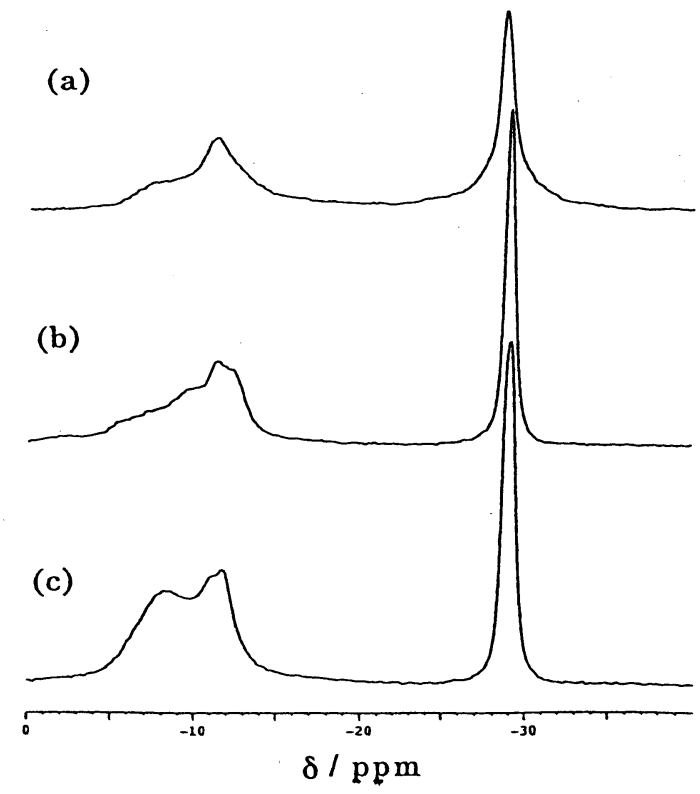

FIGURE 1. ${ }^{31 P}$ MAS NMR spectra of $\mathrm{Ce}\left(\mathrm{HPO}_{4}\right)_{2} \cdot \mathrm{nH}_{2} \mathrm{O}$ with ${ }^{1} \mathrm{H}$ high-power decoupling where $n=$ (a) 2, (b) 1.33, (c) 0.33 . 


\section{Results and Discussion}

Figure 1 shows ${ }^{31} \mathrm{P}$ MAS NMR spectra of layered $\mathrm{Ce}\left(\mathrm{HPO}_{4}\right)_{2} \cdot \mathrm{nH}_{2} \mathrm{O}(\mathrm{n}$ $=0.33,1.33$ and 2 ) with ${ }^{1} \mathrm{H}$ high-power decoupling. Two main peaks around -10 and $-30 \mathrm{ppm}$ are observed as listed in Table 1.

Alpha-form of layered phosphate has one kind of phosphate group,

TABLE 1. Chemical Shifts in $\mathrm{Ce}\left(\mathrm{HPO}_{4}\right)_{2} \cdot \mathrm{nH}_{2} \mathrm{O}$

\begin{tabular}{ccc}
\hline $\mathrm{n}$ & \multicolumn{2}{c}{$\delta / \mathrm{ppm}$} \\
\cline { 2 - 3 } & $\left(\mathrm{H}_{2} \mathrm{PO}_{4}\right)^{-}$ & $\left(\mathrm{PO}_{4}\right)^{3-}$ \\
\hline 0.33 & -11.7 & -29.0 \\
1.33 & -10.6 & -28.3 \\
2.00 & -11.2 & -28.6 \\
\hline
\end{tabular}

$\mathrm{HPO}_{4}{ }^{2-}$, whereas $\gamma$-form of layered phosphate has two chemically different kinds of phosphate groups, $\mathrm{PO}_{4}{ }^{3-}$ and $\mathrm{H}_{2} \mathrm{PO}_{4}{ }^{-3,5)}$ These three types of phosphate groups in layered zirconium and titanium phosphates have characteristic chemical shift values as shown in Fig. 2.7) The chemical shift

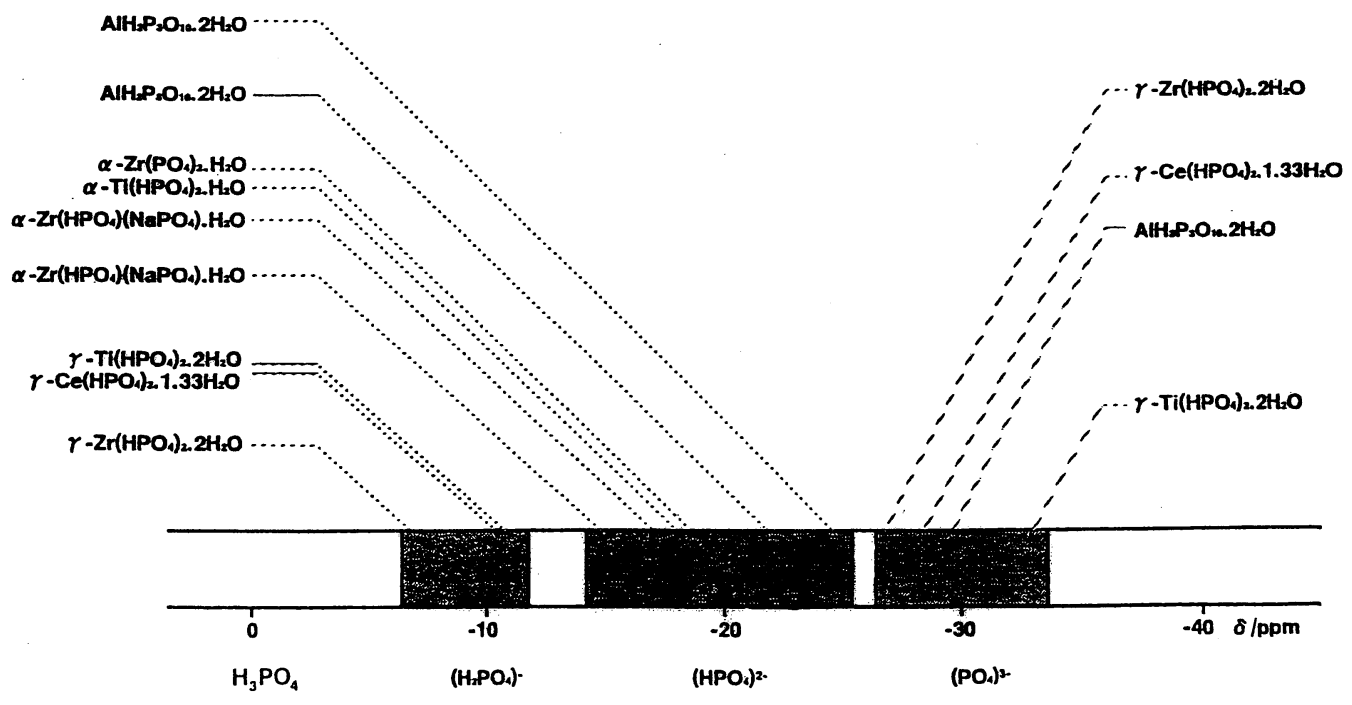

FIGURE 2. ${ }^{31} \mathrm{P}$ chemical shift values of various layered phosphates. 
values of $\mathrm{H}_{2} \mathrm{PO}_{4}^{-}, \mathrm{HPO}_{4}{ }^{2-}$, and $\mathrm{PO}_{4}{ }^{3-}$ groups are about $-10,-20$, and $-30 \mathrm{ppm}$, respectively. And the peaks in $\gamma$-form appear at around -10 and $-30 \mathrm{ppm}$, with equal intensity. Using Fig. 2, the structural type and the site of phosphate can be estimated for layered phosphate with unknown structure. $\mathrm{Ce}\left(\mathrm{HPO}_{4}\right)_{2} \cdot \mathrm{nH}_{2} \mathrm{O}(\mathrm{n}=0.33,1.33$, and 2$)$ are estimated to be $\gamma$-form. As the number of hydration water in layered cerium phosphate is nonstoichiometric, it must be careful to conclude $\mathrm{Ce}\left(\mathrm{HPO}_{4}\right)_{2} \cdot \mathrm{nH}_{2} \mathrm{O}$ ( $\mathrm{n}=0.33$, 1.33, and 2) to be $\gamma$ form.

${ }^{31} \mathrm{P}$ MAS without ${ }^{1} \mathrm{H}$ high-power decoupling and ${ }^{31} \mathrm{P}-{ }^{1} \mathrm{H}$ CP/MAS measurements were performed to confirm this conclusion. For $\mathrm{Ce}\left(\mathrm{HPO}_{4}\right)_{2}$. $1.33 \mathrm{H}_{2} \mathrm{O}$ the peak at -10.6 ppm, which will be due to $\mathrm{H}_{2} \mathrm{PO}_{4}^{-}$group, broadens without $\quad{ }^{1} \mathrm{H}$ high-power decoupling, suggesting stronger $\quad{ }^{31} \mathrm{P}-1 \mathrm{H} \quad$ dipolar interaction compared with the case of $\mathrm{PO}_{4}{ }^{3-}$ group. Contact time, $t_{\mathrm{m}}$, dependence of CP/MAS spectra elucidates

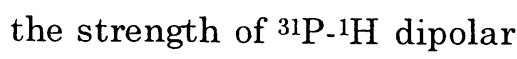
interaction semiquantitatively through crosspolarization time, $T_{\mathrm{PH}}{ }^{9)}$ Figure 3 shows CP/MAS

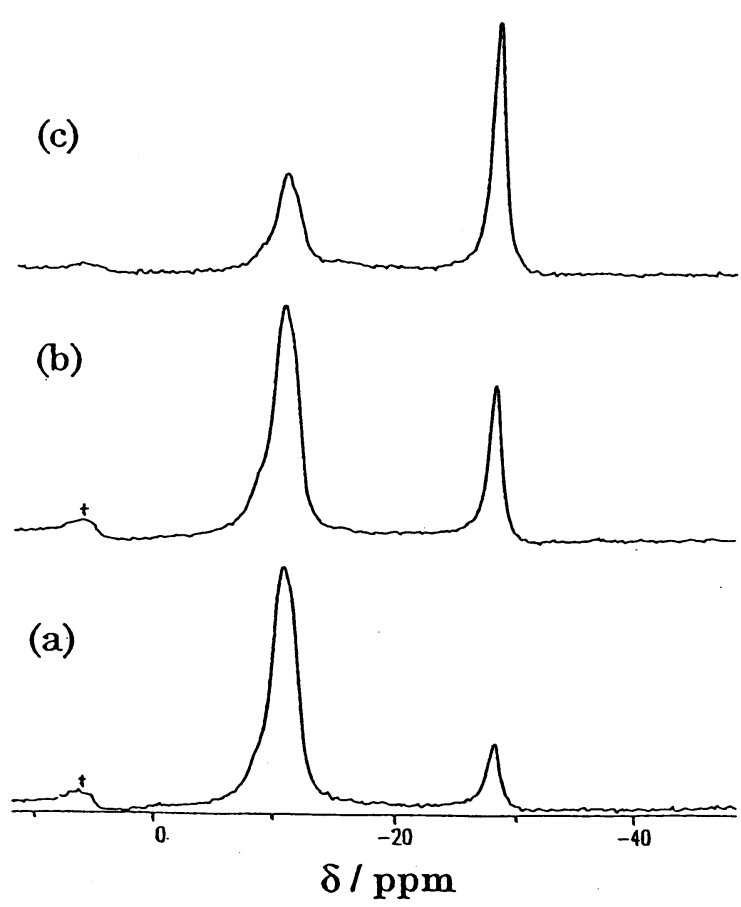

FIGURE 3. Contact time, $t_{\mathrm{m}}$, dependence of ${ }^{31} \mathrm{P}$ CP/MAS spectra of $\mathrm{Ce}\left(\mathrm{HPO}_{4}\right)_{2} \cdot 1.33 \mathrm{H}_{2} \mathrm{O}$ with $t_{\mathrm{m}}=$ (a) $100 \mu \mathrm{s}$, (b) $1 \mathrm{~ms}$, (c) $3 \mathrm{~ms}$. * shows spinning side bands. 
spectra of $\mathrm{Ce}\left(\mathrm{HPO}_{4}\right)_{2} \cdot 1.33 \mathrm{H}_{2} \mathrm{O}$ at different $t_{\mathrm{m}}$. On increasing $t_{\mathrm{m}}$, the intensity of the signal at $-10.6 \mathrm{ppm}\left(\mathrm{H}_{2} \mathrm{PO}_{4}^{-}\right.$site $)$increases within $100 \mu \mathrm{s}$, then that of the signal at $-28.3 \mathrm{ppm}\left(\mathrm{PO}_{4}{ }^{3-}\right.$ site $)$ increases. $T_{\mathrm{PH}}$ at -10.6 and $-28.3 \mathrm{ppm}$ are estimated to be $<100 \mu \mathrm{s}$ and $\sim 2 \mathrm{~ms}$, respectively. $T_{\mathrm{PH}^{-1}}$ is proportional to the $r^{-6}$ where $r$ is the distance between $\mathrm{P}$ and $\mathrm{H}$. Therefore, the peaks at -10.6 and -28.3 ppm can be assigned to $\mathrm{H}_{2} \mathrm{PO}_{4}{ }^{-}$and $\mathrm{PO}_{4}{ }^{3-}$ groups, respectively. And $T_{\mathrm{PH}}$ values are similar to the values in $\gamma$ $\mathrm{Zr}\left(\mathrm{H}_{2} \mathrm{PO}_{4}\right)\left(\mathrm{PO}_{4}\right) \cdot 2 \mathrm{H}_{2} \mathrm{O}$. The similar experiment was performed for $\mathrm{Ce}\left(\mathrm{HPO}_{4}\right)_{2} \cdot \mathrm{nH}_{2} \mathrm{O}(\mathrm{n}=0.33$ and 2). And all the forms are confirmed to be $\gamma$ form, irrespective of the number of hydration water.

The interlayer distances of cerium phosphates $(\mathrm{n}=0.33,1.33$, and 2$)$ are $14.4,16.1$, and $18.0 \AA{ }^{6}{ }^{6}$ which are considerably long compared with 11.6 $\AA$ in $\gamma-\mathrm{M}\left(\mathrm{H}_{2} \mathrm{PO}_{4}\right)\left(\mathrm{PO}_{4}\right) \cdot 2 \mathrm{H}_{2} \mathrm{O}(\mathrm{M}=\mathrm{Zr}, \mathrm{Ti})$. These differences are beyond the difference of ionic radius $\left(\mathrm{Zr}^{4+} 0.86 \AA, \mathrm{Ti}^{4+} 0.75 \AA, \mathrm{Ce}^{4+} 1.09 \AA\right)$. Although $\mathrm{Ce}\left(\mathrm{HPO}_{4}\right)_{2} \cdot \mathrm{nH}_{2} \mathrm{O}(\mathrm{n}=0.33,1.33$, and 2$)$ are $\gamma$-form, having two chemically different phosphates, $\mathrm{PO}_{4}{ }^{3-}$ and $\mathrm{H}_{2} \mathrm{PO}_{4}^{-}$, the arrangements of phosphate groups of cerium phosphates are considered to be different from those of the other layered phosphates with $\gamma$-form. The local structures of phosphate groups within three polymorphic forms are similar, that is, the existence of both $\mathrm{H}_{2} \mathrm{PO}_{4}^{-}$and $\mathrm{PO}_{4}^{3-}$ groups. The only difference is the interlayer structure, especially, the hydrogen bond scheme of water molecules, which connect the sheets of phosphates. This reflects the increase of interlayer distance by $3.6 \AA$ An increasing the amount of hydration water.

In conclusion, layered cerium phosphates, $\mathrm{Ce}\left(\mathrm{H}_{2} \mathrm{PO}_{4}\right)\left(\mathrm{PO}_{4}\right) \cdot \mathrm{nH}_{2} \mathrm{O}(\mathrm{n}=$ $0.33,1.33$, and 2 ), were confirmed to be $\gamma$-form by ${ }^{31 P}$ solid-state NMR spectra. $\mathrm{Ce}\left(\mathrm{H}_{2} \mathrm{PO}_{4}\right)\left(\mathrm{PO}_{4}\right) \cdot \mathrm{nH}_{2} \mathrm{O}(\mathrm{n}=0.33,1.33$, and 2$)$ has two different phosphate groups, $\mathrm{H}_{2} \mathrm{PO}_{4}^{-}$and $\mathrm{PO}_{4}^{3-}$, and non-stoichiometric water of 
hydration. The interlayer distances of cerium phosphates is longer than those of the other layered phosphates of $\gamma$-form.

\section{Experimental}

Hydrated cerium bis(hydrogenphosphates), $\mathrm{Ce}\left(\mathrm{HPO}_{4}\right)_{2} \cdot \mathrm{nH}_{2} \mathrm{O}(\mathrm{n}=$ $0.33,1.33$, and 2) were synthesized according to the previous method.6,8) Their compositions were determined by elemental analyses of cerium and phosphorus. X-ray diffraction patterns of the above compounds were consistent with the reported values of the interlayer spacing, $d$.

A Bruker MSL-200 and DSX-200 spectrometers operating at 81.0 $\mathrm{MHz}$ for ${ }^{31} \mathrm{P}$ were used to measure solid-state NMR spectra. A single pulse sequence with a $\pi / 2$ pulse of $2 \mu$ s with ${ }^{1} \mathrm{H}$ high-power decoupling was used for ${ }^{31} \mathrm{P}$ MAS spectra. Cross-polarization (CP) pulse sequence with ${ }^{1} \mathrm{H}$ high power decoupling was used to get ${ }^{31} \mathrm{P}$ CP/MAS spectra. Contact time, $t_{\mathrm{m}}$, dependence of ${ }^{31} \mathrm{P}$ CP/MAS spectra was measured in order to distinguish between $\mathrm{H}_{2} \mathrm{PO}_{4}^{-}$and $\mathrm{PO}_{4}{ }^{3-}$ sites in the $\gamma$-form. For the MAS and CP/MAS spectra, it was enough to accumulate 8 FD's with a recycle time of $10 \mathrm{~s}$ to get the spectra with reasonable signal to noise ratio, $\mathrm{S} / \mathrm{N}$. The MAS rate was $3-4 \mathrm{kHz}$. Chemical shift is referenced from $85 \% \mathrm{H}_{3} \mathrm{PO}_{4}$ aqueous solution.

\section{References}

1) A. Clearfield and J. A. Stynes, J. Inorg. Nucl. Chem., 26, 117 (1964).

2) A. Clearfield, R. H. Blessing and J. A. Stynes, J. Inorg. Nucl. Chem., 30, 2249 (1968).

3) J. M. Troup and A. Clearfield, Inorg. Chem., 16, 3311 (1977).

4) P. R. Rudolf and A. Clearfield, Inorg. Chem., 28, 1706 (1989).

5) D. M. Poojary, B. Shpeizer and A. Clearfield, J. Chem. Soc., Dalton Trans., 111 (1995).

6) M. Tsuhako, M. Danjo, Y. Baba, M. Murakami, H. Nariai and I. Motooka, Bull. Chem. Soc. Jpn., 70, 143 (1997).

7) H. Nakayama, T. Eguchi, N. Nakamura, S. Yamaguchi, M. Danjo and M. Tsuhako, J. Mater. Chem., 7, 1063 (1997).

8) G. Alberti, U. Costantio and L. Zsinka, J. Inorg. Nucl. Chem., 34, 3549 (1972).

9) N. J. Clayden, J. Chem. Soc. Dalton Trans., 1877 (1987). 